\title{
Gestão do conhecimento, aprendizagem móvel e direito do consumidor: estratégia para acesso à informação
}

\section{Alternative Title: Knowledge management, mobile learning and consumer law: strategy for access to information}

\author{
Elias Ricardo de Oliveira \\ Universidade Federal Rural de Pernambuco \\ Recife, Pernambuco, Brasil \\ +558199114-8130 \\ eliasrick872@hotmail.com
}

\author{
Juliana Regueira Basto Diniz \\ Universidade Federal Rural de Pernambuco \\ Recife, Pernambuco, Brasil \\ +55 813320-6478 \\ julianabdiniz@gmail.com
}

\begin{abstract}
RESUMO
Este estudo tem por objetivo apresentar os resultados de pesquisa realizada sobre a utilização da gestão do conhecimento atrelada a tecnologia móvel para a promoção dos direitos do consumidor. A utilização das informações por meio da aprendizagem móvel resultou em um aplicativo que disponibiliza a informação na temática estudada ao mesmo tempo em que promove acesso aos serviços da delegacia do consumidor de Pernambuco e outros órgãos de defesa dos direitos deste consumidor. Além deste, uma cartilha informativa foi desenvolvida e disponibilizada para que possa ser impressa e ser utilizada em um curso na modalidade a distância, por meio de um ambiente virtual de aprendizagem, a profissionais de segurança pública da região metropolitana do Recife e interior do estado de Pernambuco.
\end{abstract}

\section{Palavras-Chave}

Gestão do conhecimento, direito do consumidor, aprendizagem móvel.

\begin{abstract}
This paper aims to present the results of a research carried out on the use of knowledge management with mobile technology to promote of consumer law. The use of information through mobile learning resulted in an application that provides the information and promoter access to the services of the consumer police station of Pernambuco and to other consumer protection agencies. In addition, an information booklet was developed and made available to be used in an e-learning course, using a virtual environment for public security safety with in the Recife metropolitan region and other actus in the countryside of Pernambuco.
\end{abstract}

\section{CCS Concepts}

Human-centered computing Smartphones.

\section{Keywords}

knowledge management, consumer law, mobile learning.

Permission to make digital or hard copies of all or part of this work for personal or classroom use is granted without fee provided that copies are not made or distributed for profit or commercial advantage and that copies bear this notice and the full citation on the first page. To copy otherwise, or republish, to post on servers or to redistribute to lists, requires prior specific permission and/or a fee.

SBSI 2017, Jun 05-08, 2017, Lavras, Minas Gerais, Brazil.

Copyright SBC 2017

\section{INTRODUÇÃO}

Consumidores que não conhecem seus direitos e/ou o local correto para realizar uma reclamação foi o ponto de partida desta pesquisa. $\mathrm{Na}$ Delegacia do Consumidor (DECON) de Pernambuco todos os dias comparecem cidadãos que tiveram seus direitos negados por empresas e fornecedores. Diante da situação o consumidor necessita que uma instituição legalmente constituída possa fazer com que seus direitos sejam respeitados. Ocorre que muitas vezes o local mais indicado para buscar orientação não é na DECON. Existem muitos órgãos de defesa do consumidor, entre eles: Ministério Público de Pernambuco (MPPE), PROCON, Defensoria Pública, entre outros.

Por outro lado, o conhecimento empírico da DECON por meio de seus agentes policiais que trabalham diuturnamente na investigação e prevenção de crimes nas relações de consumo, é difuso, espalhado entre os servidores, necessitando por vezes de consultas entre os pares ou ao código de defesa do consumidor (CDC) para sanar dúvidas. Necessita de organização e disponibilização para que, estrategicamente, possa ser oferecido ao cidadão e assim obter economia de tempo para ambas as partes - consumidor e Estado.

A Gestão do Conhecimento (GC) pode ser utilizada para que este conhecimento empírico seja canalizado, organizado e oferecido ao cidadão de forma simples e rápida. Desta forma, a utilização de dispositivos móveis para a divulgação destas informações tornar-se não apenas atraente quanto necessária.

Portanto, o direito do consumidor deve, conforme o CDC, ser divulgado para a população Estado de forma a torna-la capaz de discernir e buscar informações/resolução junto aos órgãos competentes. Para tanto, esta pesquisa propôs, por meio da Gestão do Conhecimento e através do uso de dispositivos móveis, uma alternativa distinta para a problemática apresentada: um aplicativo que promova o acesso a informação sobre os direitos dos consumidores e cartilha informativa para uso das delegacias e curso na modalidade de educação a distância, ambos denominados de "ConsumidorAtento".

Nas próximas seções deste artigo serão descritos: na seção 2 fundamentação teórica; seção 3 - procedimentos metodológicos utilizados; seção 4 - resultados obtidos na pesquisa; seção 5 produtos resultantes e seção 6 - conclusão e trabalhos futuros.

\section{FUNDAMENTAÇÃO TEÓRICA}

\subsection{Gestão do Conhecimento}

A gestão do conhecimento é um campo de investigação relativamente emergente e bastante valorizado nos tempos atuais 
[1]. A GC quando bem gerida cria um ambiente social e tecnológico favorável para atividades relacionadas com o conhecimento que promovam a criação, o armazenamento e o compartilhamento deste conhecimento [2].

Por outro lado, uma GC também promove a inovação, aumenta a eficiência a eficácia, além de elevar a colaboração melhorando os níveis de conhecimento dos empregados, pois qualifica os processos como o de tomada de decisões [3].

Segundo [4] a gestão do conhecimento é investigada tendo como base teorias provenientes de diversas áreas, entre elas: gestão estratégica, cultura organizacional, comportamento organizacional e sistemas de informação.

Já para [5] a gestão do conhecimento é uma área na união entre a tecnologia de informação com a administração, um campo entre a estratégia, cultura e os sistemas de informação de uma organização, podendo serem públicas ou privadas. Através da gestão do conhecimento, começa-se a ver a empresa, suas estratégias e sua cultura.

A gestão do conhecimento organizacional, segundo [6] é um conjunto de processos que governa a criação, a disseminação e a utilização de conhecimento no âmbito das organizações. É apresentado na tabela 1 por [7] uma visão extensiva sobre alguns conceitos relacionados a GC.

Tabela 1. Visão e conceituação de gestão do conhecimento

\begin{tabular}{|c|c|}
\hline Referências & Visão - Conceituação \\
\hline [5] & $\begin{array}{l}\text { A gestão do conhecimento é uma nova área na } \\
\text { união entre a tecnologia de informação e } \\
\text { administração, um campo novo entre a } \\
\text { estratégia, a cultura e os sistemas de informação } \\
\text { de uma organização. }\end{array}$ \\
\hline [6] & $\begin{array}{l}\text { A gestão do conhecimento é à arte e processo de } \\
\text { criar valor a partir dos ativos intangíveis da } \\
\text { organização. }\end{array}$ \\
\hline [8] & $\begin{array}{l}\text { Traz em linhas gerais que a Gestão do } \\
\text { conhecimento é como um processo, pelo qual as } \\
\text { organizações buscam novas formas de criar, e } \\
\text { expandir o conhecimento. }\end{array}$ \\
\hline [25] & $\begin{array}{l}\text { A gestão do conhecimento é como uma } \\
\text { metodologia de gerenciamento que se preocupa } \\
\text { com as estratégias para alcançar a inteligência } \\
\text { competitiva. }\end{array}$ \\
\hline [26] & $\begin{array}{l}\text { Gestão do Conhecimento é um conjunto de } \\
\text { ações que procura identificar, capturar, } \\
\text { gerenciar e compartilhar as informações da } \\
\text { organização. }\end{array}$ \\
\hline [27] & $\begin{array}{l}\text { Gestão do conhecimento é a criação, } \\
\text { disseminação e utilização do conhecimento a } \\
\text { partir de um conjunto de processos } \\
\text { organizacionais. }\end{array}$ \\
\hline [28] & $\begin{array}{l}\text { A gestão do conhecimento é o núcleo de } \\
\text { organização de ativos intangíveis que interfere } \\
\text { positivamente o desempenho de uma empresa. }\end{array}$ \\
\hline
\end{tabular}

Embora existam diversos conceitos acerca do quem vem a ser a GC, este trabalho adota o que foi proposto por [8], já que o código de defesa do consumidor trata de direito coletivo e neste campo é importante a estratégia para a expansão do conhecimento junto aos cidadãos.

Quando se sugere disponibilizar o conhecimento adquirido e existente na legislação vigente do CDC para o usuário/consumidor, este processo encontra respaldo fundamental na $\mathrm{GC}$, pois proporcionar comunicação entre as pessoas envolvidas com o conteúdo do CDC gera um bom nível de satisfação do cliente [29] de forma que possam executar os processos da melhor maneira possível. Os autores acrescentam que para alcançar tais objetivos, as informações referentes aos processos e à administração da empresa precisam ser mensuradas e organizadas. Estas informações que são geradas dependem entre outros fatores do tipo de arquitetura computacional [30].

Desta forma, o conteúdo trabalhado e disponibilizado pelo aplicativo "ConsumidorAtento" atende a estes requisitos de forma simples e prática, disponibilizando o conteúdo sobre direitos e deveres dos consumidores além de direcioná-los para o local mais adequado na resolução de seu conflito, pois "gestão do conhecimento é identificar o que se sabe, captar e organizar este conhecimento e utilizá-lo de forma a gerar retornos. " [2]. Para além, a extenalização do conhecimento é muito importante para a gestão do conhecimento pois o relato de experiências vivenciadas pode contribuir para resolução de problemas futuros e melhorias de processos e produtos [31].

\subsection{Aprendizagem Móvel}

A aprendizagem móvel através de tecnologias portáteis, tais como smartphone, laptop, telefone celular e o tablet ou computador de mão, vai além da própria tecnologia, apresentando três conceitos de aprendizagem móvel: a partir de equipamentos ou ferramentas (Dispositivos Móveis e tecnologias - DMs); a partir de ações, experiências de aprendizagem com os DMs; e a partir dos interagentes, considerando a mobilidade dos aprendizes e da aprendizagem [9].

Em se tratando de dispositivos móveis, alguns requisitos necessários para uso no m-learning voltados a partir das perspectivas dos alunos são: adaptabilidade do conteúdo, informações disponíveis, possibilidade de configuração, um conteúdo compreensível, autoinstrução, adequação de conteúdo de acordo com as diretrizes da instituição de ensino e um assunto interessante e agradável [10].

O aplicativo e a cartilha, desenvolvidos através deste trabalho e disponibilizados para os consumidores, têm como base essas premissas, pois procura agregar conhecimento ao usuário.

A aprendizagem é facilitada por meio da tecnologia móvel, pois qualquer pessoa pode transportar uma ferramenta de aprendizagem no bolso e todas utilizam essas ferramentas na prática social delas, já que são relativamente de baixo custo e fáceis de manusear e é possível utilizá-las em diversos contextos [11].

A UNESCO ao lançar as diretrizes de políticas para aprendizagem móvel realça que esta envolve o uso de tecnologias móveis, isoladamente ou em combinação com outras tecnologias de informação e comunicação (TIC), a fim de permitir a aprendizagem a qualquer hora e em qualquer lugar [12].

\subsection{Direito do Consumidor}

O consumidor é considerado sujeito vulnerável nas relações de consumo e no art. $4^{\circ}$, inc. I, do CDC é constatada a evidente intenção do legislador em proteger o consumidor, em todas as situações, da condição de vulnerabilidade na relação jurídica de consumo. Onde "de acordo com a realidade da sociedade de consumo, não há como afastar tal posição desfavorável, principalmente se forem levadas em conta as revoluções pelas quais passaram as relações jurídicas e comerciais nas últimas décadas." [13].

Neste sentido, destaca-se que o consumidor é "sem dúvida a parte mais fraca, vulnerável, pois os detentores dos meios de produção são os que detêm todo o controle do mercado, ou seja, sobre o que produzir, como produzir, sem falar-se na fixação de suas margens de lucro" [14]. 
Neste ponto, ao se falar em relações de consumo, invariavelmente é inserida a ideia de vulnerabilidade do consumidor, pois diante de um comércio tão acirrado que detêm todas as estratégias para uma publicidade persuasiva e incisiva, utilizando-se por vezes da linguagem complexa para a exposição de produtos e serviços não comuns e supérfluos, deixa o consumidor em posição de desvantagem, colocando-o propenso ao consumo das tendências do comércio [15].

Algumas peculiaridades publicitárias incidem sobre o consumidor por meio de campanhas enganosas na oferta de produtos, atribuindo ao anúncio curas miraculosas de determinados produtos ou a descoberta de produtos substitutivos de alimentos; também com contratos pré-elaborados, com cláusulas pré-restritivas de direitos, ou leoninas; bem como, ajustes com textos de difícil leitura para o consumidor comum; excessos de garantias e outras situações de latente desequilíbrio têm sido frequentes na contratação privada, lesando-se os interesses de ordem econômica dos consumidores envolvidos na transação, indefesos ante os apelos publicitários agressivos e a necessidades existentes ou criadas pela sociedade de consumo [16].

\section{TRABALHOS CORRELATOS}

A revisão da literatura (RS) objetivou identificar artigos que versassem sobre o ensino do direito do consumidor através de artefatos tecnológicos, notadamente por meio de dispositivos móveis.

Não foram encontrados trabalhos efetivos com esta temática. Contudo, foi identificado que existem iniciativas relacionadas ao ensino e aprendizagem neste ramo com uso da educação a distância.

As duas iniciativas identificadas são do Governo Federal, onde a primeira dar-se através do Instituto Legislativo Brasileiro (ILB) do Senado Federal, por meio da plataforma "Saberes"1", onde funcionários do Senado Federal podem realizar cursos com o acompanhamento de tutoria online. Contudo, este curso não é exclusivo para servidores do senado, os cidadãos também podem participar, neste caso, sem tutoria. O curso oferecido possui diversas categorias que envolvem desde o estudo de direito nas suas diversas áreas até ética e administração pública, entre eles, o curso de Introdução ao Direito do Consumidor, todos disponibilizados e disponíveis através da educação a distância.

O curso oferecido pelo ILB possui carga horária de 40h e duração de 60 dias com o conteúdo introdutório do direito do consumidor divido em sete módulos. Oferecido através da plataforma Moodle que "é uma plataforma de aprendizagem a distância baseada em software livre. É um acrônimo de Modular Object-Oriented Dynamic Learning Environment (ambiente modular de aprendizagem dinâmica orientada a objetos)" [17].

Ainda neste contexto de identificação do ensino do direito do consumidor através de artefatos tecnológicos foi realizada pesquisa com busca automática na Google Play com fito de identificar quais aplicativos móveis versam sobre o Código de Defesa do Consumidor (CDC).

Com a palavra-chave 'consumidor' inserida no motor de busca, o Google Play reportou 98 aplicativos, dentre estes, 20 faziam referências diretas ao CDC. Já os restantes eram aplicativos sem conexão com a temática pesquisada.

Dentre os aplicativos reportados, destacamos alguns e suas principais características, seus desenvolvedores e data da

\footnotetext{
${ }^{1}$ Plataforma Moodle, sítio http://saberes.senado.leg.br/
}

disponibilização do aplicativo e ou de sua atualização. Os aplicativos selecionados possuem diversas característica distintas entre si, porém a maioria deles se limitavam a apresentar a lei na íntegra, ou seja, uma versão digital do código de defesa do consumidor (CDC). Desta forma, dos 20 aplicativos reportados, 12 deles eram a versão digital do CDC.

Diante dos aplicativos elencados na tabela 2 é possível perceber que boa parte deles são as versões digitais do CDC, enquanto outros são extensões dos serviços oferecidos pelos órgãos de fiscalização e/ou revistas/associações de proteção aos direitos do consumidor. Apenas um é oferecido como um jogo, contudo, não no intuito de ensino, como nos jogos digitais para educação, e sim como entretenimento, a fim de incentivar o consumo de bens e serviços.

Tabela 2. Aplicativos reportados em pesquisa no Google Play

\begin{tabular}{|c|c|c|}
\hline Aplicativo & Característica & Desenvolvedor \\
\hline Consumidor.gov.br & $\begin{array}{l}\text { Resolução de } \\
\text { problemas nas } \\
\text { relações de } \\
\text { consumo. }\end{array}$ & Latitude UnB \\
\hline "ProtesteAgora" & $\begin{array}{l}\text { Canal de } \\
\text { reclamações com o } \\
\text { desenvolvedor }\end{array}$ & Proteste \\
\hline $\begin{array}{l}\text { Código de Defesa do } \\
\text { Consumidor }\end{array}$ & Lei na Íntegra & $\begin{array}{l}\text { luizcarlosoliveir } \\
\text { acontato@gmai } \\
\text { l.com }\end{array}$ \\
\hline Anatel Consumidor & $\begin{array}{l}\text { Registro e } \\
\text { acompanhar } \\
\text { reclamação da } \\
\text { agência nacional }\end{array}$ & ANATEL \\
\hline $\begin{array}{l}\text { Código de Defesa do } \\
\text { Consumidor }\end{array}$ & Lei na Íntegra & $\begin{array}{l}\text { Carlos Alberto } \\
\text { Pinto }\end{array}$ \\
\hline $\begin{array}{l}\text { Código de Defesa do } \\
\text { Consumidor }\end{array}$ & Lei na Íntegra & $\begin{array}{l}\text { F\&E System } \\
\text { Apps }\end{array}$ \\
\hline Meu Procon RJ & $\begin{array}{l}\text { Fazer reclamações, } \\
\text { tirar dúvidas, } \\
\text { denúncias, etc. }\end{array}$ & PRODERJ \\
\hline PROCON MA 2.0 & $\begin{array}{l}\text { Fazer denúncias, } \\
\text { acompanhar } \\
\text { notícias, etc. }\end{array}$ & $\begin{array}{l}\text { Igor Leonardo } \\
\text { Salomão de } \\
\text { Sousa } \\
\text { (PROCON } \\
\text { Maranhão) }\end{array}$ \\
\hline Jogo do Consumidor & $\begin{array}{l}\text { Incentivo ao } \\
\text { consumo }\end{array}$ & $\begin{array}{l}\text { Artnoc Network } \\
\text { (UNILEVER) }\end{array}$ \\
\hline Procon Carioca & $\begin{array}{l}\text { Fazer reclamações, } \\
\text { tirar dúvidas, } \\
\text { denúncias, etc. }\end{array}$ & Felipe Teixeira \\
\hline "ProtesteAqui" & $\begin{array}{l}\text { Compartilhamento } \\
\text { de reclamações }\end{array}$ & $\begin{array}{l}\text { DECO } \\
\text { PROTESTE }\end{array}$ \\
\hline
\end{tabular}

Já existem alguns aplicativos lançados no mercado que disponibilizam o Código de Defesa do Consumidor para consulta, fornecem endereços de instituições/órgão de defesa do consumidor, dentre outros. Como exemplo, o PROCON do Estado do Maranhão lançou um aplicativo com as seguintes características: possibilidade de acessar as notícias atualizadas sobre a atuação do órgão (PROCON MA) em todo estado, acesso as redes sociais, e informações sobre o posto de atendimento mais próximo. Um ponto do aplicativo do PROCON do Maranhão é a possibilidade de denunciar algum abuso contra o consumidor, desta forma o usuário 
pode enviar uma foto-denúncia junto com a localização por meio do GPS integrado ao aplicativo.

Já no estado do Rio de Janeiro, o PROCON estadual lançou um aplicativo para que reclamações dos consumidores possam ser realizadas através do dispositivo móvel, além disso, disponibiliza um espaço para que as principais dúvidas destes consumidores sejam sanadas com perguntas e respostas.

É possível verificar que, em ambos os órgãos, são oferecidas as extensões de seus serviços aos consumidores, proporcionando mais comodidade na prestação destes.

\subsection{Gestão do Conhecimento em Instituições Policiais}

As tentativas para implantar a gestão do conhecimento em instituições públicas, especialmente nas instituições policiais vem crescendo ao longo dos anos.

Destacamos a experiência do Estado de Minas Gerais (MG) que por meio da Política Estadual de Gestão do Conhecimento ${ }^{2}$ propôs a implementação da GC na polícia civil.

Através de um projeto piloto, a Polícia Civil de Minas Gerais (PCMG), teve a oportunidade de participar de capacitações em GC promovidas pela Secretaria de Planejamento e Gestão de MG em parceria com o Instituto de Pesquisa Econômica e Aplicada (IPEA), recebendo instruções de como poderia implementar a GC no âmbito institucional para produzir resultados em benefício ao cidadão.

Após a análise inicial e planejamento da GC no âmbito da PCMG, identificou-se algumas lacunas que deveriam ser trabalhadas, conforme tabela 3:

Tabela 3. PCMG: lacunas/problemas relativos ao conhecimento organizacional

\begin{tabular}{|l|l|}
\hline $\begin{array}{l}\text { Lacunas/problemas } \\
\text { relativos ao } \\
\text { conhecimento } \\
\text { organizacional }\end{array}$ & Objetivo geral \\
\hline $\begin{array}{l}\text { Atendimento ao } \\
\text { cidadão }\end{array}$ & $\begin{array}{l}\text { Melhorar a satisfação do cidadão aplicando os } \\
\text { conhecimentos obtidos com as melhores práti- } \\
\text { cas de atendimento ao público. }\end{array}$ \\
\hline $\begin{array}{l}\text { Conhecimento tácito } \\
\text { dos servidores }\end{array}$ & $\begin{array}{l}\text { Reter o conhecimento dos servidores } \\
\text { formalizando suas experiências obtidas ao } \\
\text { longo de sua carreira policial, de forma a } \\
\text { viabilizar a difusão de informações. }\end{array}$ \\
\hline Gestão da frota & $\begin{array}{l}\text { Aumentar a eficiência e a eficácia da gestão da } \\
\text { frota de veículos da PCMG por meio de } \\
\text { ferramenta capaz de subsidiar o planejamento } \\
\text { de aquisições, utilização, manutenção, abaste- } \\
\text { cimento, distribuição e alocação. }\end{array}$ \\
\hline $\begin{array}{l}\text { Gestão do } \\
\text { conhecimento } \\
\text { finalístico }\end{array}$ & $\begin{array}{l}\text { Criar mecanismos que propiciem a difusão do } \\
\text { conhecimento sobre métodos de investigação } \\
\text { destinados à elucidação de crimes entre os } \\
\text { policiais civis, com vistas a padronizar e } \\
\text { aperfeiçoar metodologias específicas de } \\
\text { apuração de infrações penais. }\end{array}$ \\
\hline Mapentos & $\begin{array}{l}\text { Mapear dados profissionais e acadêmicos dos } \\
\text { servidores da PCMG com o intuito de } \\
\text { identificar potenciais talentos. }\end{array}$ \\
\hline
\end{tabular}

\footnotetext{
${ }^{2}$ Resolução Seplag/MG no 55, de 27 de julho de 2012
}

\section{METODOLOGIA}

A realização de qualquer trabalho de investigação é inerente a recolha de dados, tornando-se necessária a programação das ações a desenvolver para a sua execução [18].

De natureza aplicada, a pesquisa objetiva uma abordagem prática para a solução de um problema específico [19]: direcionar o cidadão para o órgão competente na solução de seu problema na relação de consumo. Além disto, disponibilizar as informações que possam ser utilizadas para prevenção de problemas consumeristas.

Neste sentido, levando-se em consideração a escolha pela abordagem do problema e com a produção de dados primários, além do levantamento dos secundários, optou-se por uma abordagem quantitativa [20] para identificação dos problemas enfrentados pelos consumidores e a percepção/utilização no uso de dispositivos móveis. Num segundo momento, após a versão final do protótipo, outra pesquisa para avaliar a viabilidade do protótipo [21] foi realizada para que o público alvo pudesse sugerir melhorias e apontar suas percepções acerca do uso do aplicativo "ConsumidorAtento".

Devido ao grande número de consumidores se dirigirem a DECON para solução ou encaminhamento de seus problemas consumeristas, optou-se, após a coleta dos dados secundários, identificar quais "as razões inconscientes e ocultas porque, por exemplo, o consumidor utiliza determinado produto ou que determinam certos comportamentos ou atitudes"[18].

Neste ponto, a possibilidade no potencial dos dispositivos móveis para promoção da inteligência coletiva por meio da informação, revela uma pesquisa também descritiva, com objetivo de identificar os fatores das causas deste fenômeno [22].

A necessidade de se conhecer as motivações que levam o consumidor a ir em busca de ajuda em vários locais distintos para solução de seu problema numa relação de consumo é um dos fatores para o ponto de partida desta pesquisa.

Destaca-se que o método adotado foi dividido em três momentos os quais se conectam com a temática central. O primeiro deles foi o levantamento dos registros realizados, por meio dos boletins de ocorrência na DECON, sobre problemas relacionados a alimentos em supermercados de Pernambuco - dados secundários, posteriormente a realização de pesquisa primária para traçar perfil do público alvo e aceitação da tecnologia sugerida e por último um teste no protótipo do aplicativo "ConsumidorAtento".

\section{RESULTADOS 5.1 Pesquisa - público alvo e aceitação da tecnologia}

A pesquisa realizada com o público-alvo identificou, conforme [20], das 84 pessoas pesquisadas, $56 \%$ conheciam o CDC e que $60,7 \%$ já tiveram seus direitos negados, enquanto consumidores.

Assim como na pesquisa realizada, os dados apontados pelo portal [23] mostram que as principais reclamações dos consumidores referem-se a cartão de crédito/débito/loja $(9,4 \%)$, telefonia móvel pós-paga $(9,3 \%)$, TV por assinatura $(8,7 \%)$, aparelho celular $(7,9 \%)$, telefonia fixa $(6,3 \%)$, telefonia móvel pré-paga $(6,2 \%)$, pacote de serviços - combo $(5,4 \%)$, internet fica $(5,3 \%)$, internet móvel $(4,3 \%)$ e poupança/conta aposentadoria/conta corrente/salário somam 3,4\% das reclamações [20]. 
Diante da identificação da problemática estudada a pesquisa avança e alcança a tecnologia, onde $78,6 \%$ dos pesquisados responderam que utilizam a internet no dia a dia e com uso de dispositivos móveis, o resultado foi de $94 \%$ positivamente [20].

No uso do sistema operacional, foram questionados sobre "qual o sistema operacional?" o seu dispositivo móvel funciona, onde no gráfico 1 se tem o resultado.

Gráfico 1. Sistemas operacionais utilizados por consumidores

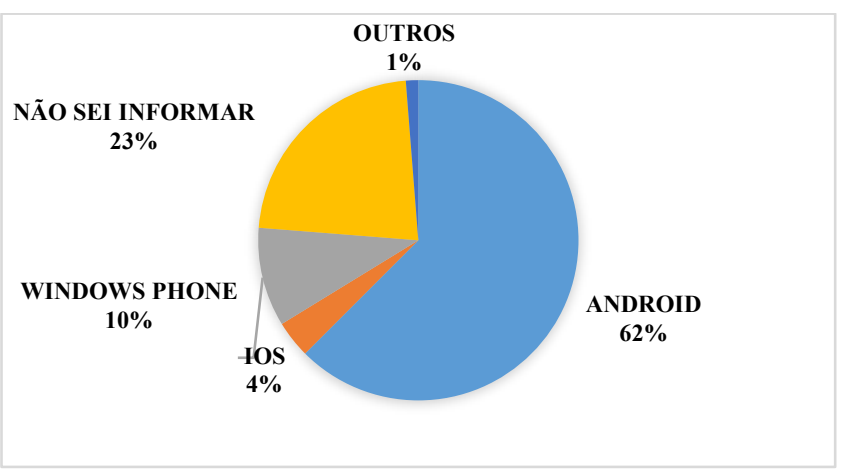

Segundo mesma pesquisa [20], ao serem perguntados sobre se "utiliza com frequência aplicativos de seu smartphone?", 72,6\% afirmaram positivamente, enquanto $27,4 \%$ disseram não usar aplicativos. Já em relação a se "tem algum aplicativo instalado para aprendizagem?", $57,1 \%$ responderam que sim, enquanto $42,9 \%$ negaram.

No caso da temática estudada, direitos do consumidor, os pesquisados responderam $(77,8 \%)$ ter algum aplicativo com essa temática, contudo, quando perguntados se "lembram qual foi?" $86,5 \%$ disseram que não lembravam e $13,5 \%$ que sim, embora não escreveram em espaço disponível para qual o aplicativo utilizado na defesa do consumidor [20].

A última questão desta pesquisa referia-se a uma ação positiva de se no "caso existisse um aplicativo voltado para o ensino sobre as leis do consumidor, você acredita que faria o download/baixaria o aplicativo?" onde as respostas foram quase uma unanimidade nesta questão com $94 \%$ afirmando que sim [20].

\subsection{Aplicativo}

"ConsumidorAtento" possui como premissa oferecer uma aproximação do consumidor com a DECON, pois além de oferecer a extensão dos serviços oferecidos fisicamente a este consumidor, disporá da possibilidade de envio de denúncia sem que deseje ou necessite da confecção de um boletim de ocorrência. Além disto, o aplicativo tem por objetivo o de proporcionar através de uma linguagem acessível acesso a informação na temática do CDC e com isto ir além no serviço disponibilizado pelo Estado, já que este consumidor será um potencial multiplicador dos conhecimentos adquiridos através do aplicativo.

O aplicativo foi desenvolvido por meio da plataforma APPInventor que é uma ferramenta desenvolvida pela Google e, atualmente, mantida pelo Instituto de Tecnologia de Massachusetts (MIT), que permite a criação de aplicativos para smartphones que rodam o sistema operacional Android, sem que seja necessário conhecimento em programação.

Umas das principais vantagens do APPInventor é a possibilidade daqueles que não possuem conhecimento em linguagem de programação poderem realizar a produção de um aplicativo, pois trabalha com a linguagem visual (à base de blocos) - na qual você vai encaixando um bloco noutro como se fosse um quebra-cabeça.
O APPInventor é uma plataforma gratuita e estável e que embora seja considerada uma versão Beta está disponível desde o ano de 2010.

Atualmente a versão conhecida da plataforma é o APPInventor2 que conta, inclusive, com uma versão em português do Brasil.

Na figura 1 observa-se a construção da parte da programação do aplicativo, por meio dos blocos.

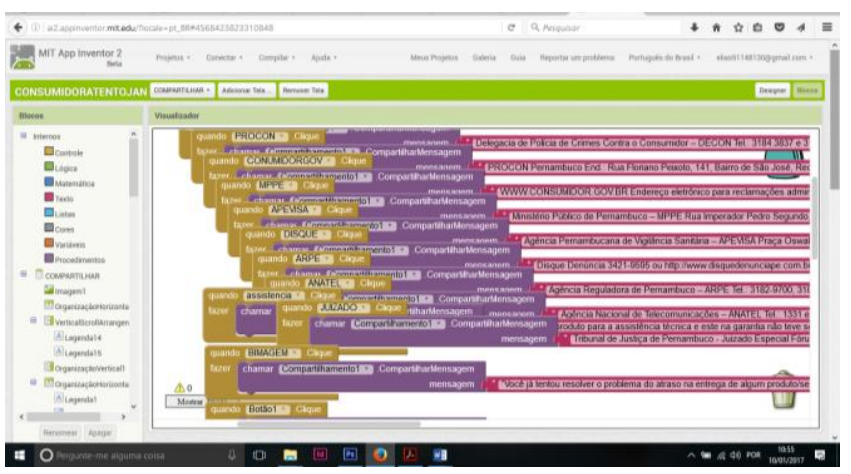

Figura 1. Modulo "blocos" do APPInventor para o botão "Compartilhar" do aplicativo

Embora a figura 1 apresente muitos blocos ensejando ideia de complexidade, na prática, não é o que ocorre. A depender do objetivo do aplicativo, a construção é mais repetitiva do que complexa.

Dentre as funcionalidades, destacam-se: informação sobre as principais dúvidas; como denunciar; compartilhamento de dicas e endereços; telefones/contatos com acesso a ligações podendo serem realizadas pelo próprio aplicativo, além de visualização do locais onde buscar ajuda por meio do googlemaps.

$\mathrm{Na}$ figura 2 é possível ver a tela inicial do aplicativo.

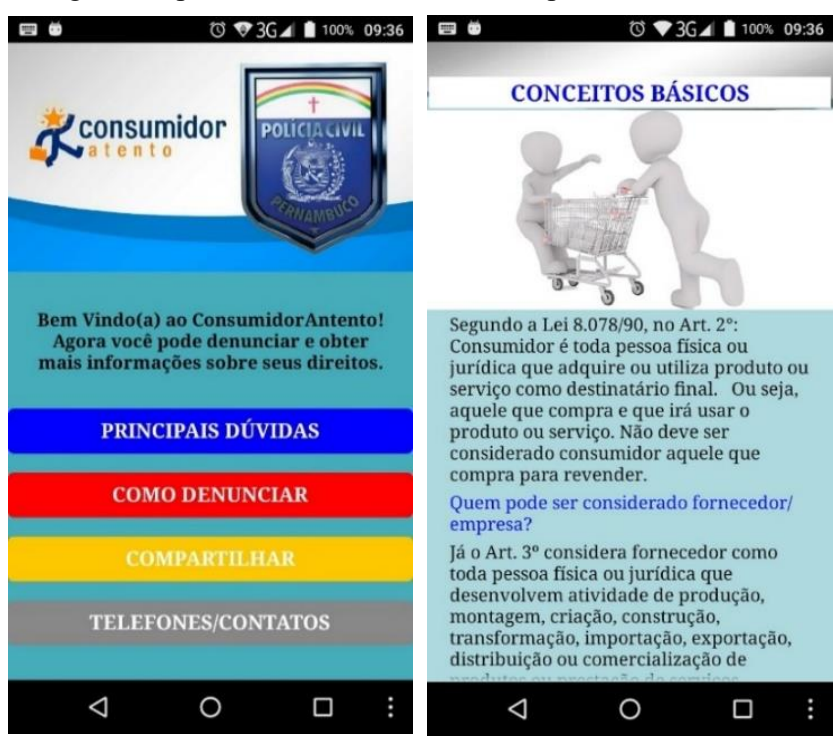

Figura 2. Telas iniciais do aplicativo "ConsumidorAtento"

No botão "principais dúvidas" o aplicativo contém as principais queixas dos consumidores quando se deparam com problemas relacionados ao consumo. Com linguagem simples e acessível, informa qual o melhor caminho a seguir para a resolução do conflito de forma eficaz.

Caso o consumidor deseje ou necessite denunciar, no botão "como denunciar" obterá acesso a forma e local mais adequado para 
realizar a denúncia, quer seja um crime relacionado ao consumo ou um problema administrativo que não obteve resolução junto a prestadora de serviço/produto, até mesmo situações que envolvam reparação de danos moral e material.

Já no botão "compartilhar" é possível realizar compartilhamentos de dicas importantes sobre os direitos do consumidor. Este compartilhamento poderá ser realizado por meio de redes sociais e/ou e-mails. Além disto, também é possível divulgar os contatos telefônicos, e-mails e endereços físicos das principais instituições de defesa do consumidor.

Por meio do botão "telefones/contatos" o usuário poderá efetivar ligações através do botão "ligar" sem necessidade de anotar o número de telefone da instituição. Poderá ainda acessar o endereço eletrônico de cada local clicando no ícone correspondente.

Outra facilidade é a possibilidade de verificar através do googlemaps qual a localização da instituição dentro do próprio aplicativo. Estas informações são importantes, pois diversos consumidores informam na DECON que o número de telefone que adquiriram na internet estava incorreto ou desatualizado, bem como o endereço por vezes também estava errado.

Desta forma, na figura 3 é possível identificar por meio do aplicativo "ConsumidorAtento" qual o endereço correto e telefones dos órgãos de defesa do consumidor.

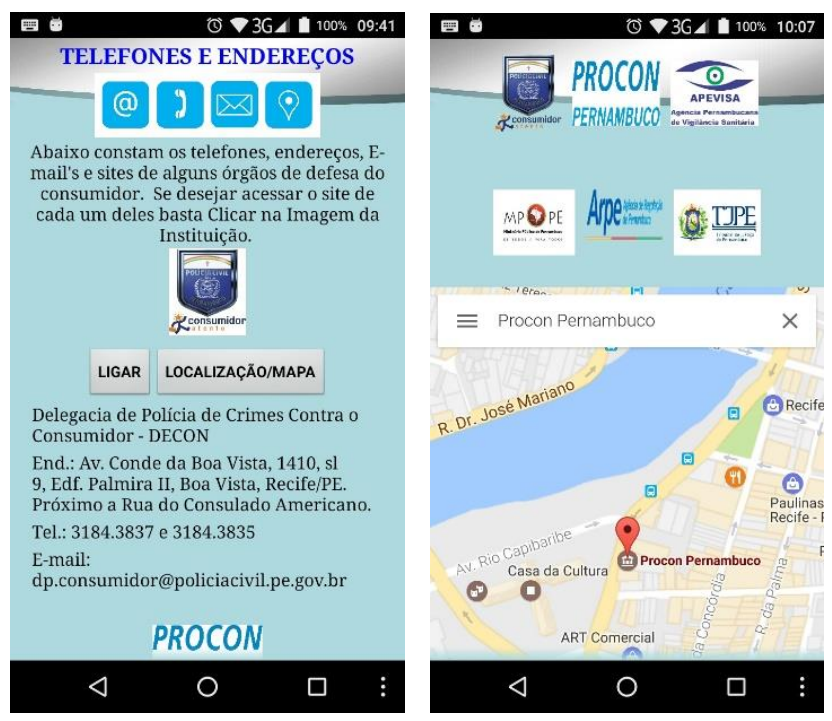

Figura 3. Telas que indicam telefones e endereços

\subsection{Teste do Protótipo/Aplicativo}

Antes de disponibilizar a versão final do aplicativo, foi realizada uma pesquisa de intenção e usabilidade do protótipo "ConsumidorAtento".

Foram seis pessoas que testaram, durante $48 \mathrm{~h}$, o protótipo do aplicativo e assim responderam a pesquisa. Estas pessoas possuíam as mesmas características do público-alvo da pesquisa primária desenvolvida.

Nos testes realizados foi possível identificar a variedade das versões do Android em que o aplicativo rodou, bem como no tamanho das telas e capacidade de processamento destes equipamentos.

Verificou-se também a prevalência em 50\% na marca destes equipamentos (Samsung), contudo o critério de escolha para os testes não foram as marcas ou modelos, e sim os usuários, estes escolhidos de acordo com o perfil dos usuários identificados na pesquisa primária já realizada neste trabalho.

$\mathrm{Na}$ tabela 4 é apresentado um resumo dos aparelhos que foram utilizados nos testes e suas configurações básicas.

Tabela 4. Aparelhos utilizados e versões do Android

\begin{tabular}{|l|l|l|}
\hline Marca & Modelo & Versão \\
\hline Samsung & Galaxy S3 & 4.3 Jelly Bean \\
\hline Samsung & J7 & 6.0.1 Marshmallow \\
\hline Samsung & J2 & 5.1 Lollipop \\
\hline Motorola & Moto G3 & 5.1.1 Lollipop \\
\hline Leagoo & M5 & 6.0 Marshmallow \\
\hline Zopo & Hero 2 & 6.0 Marshmallow \\
\hline
\end{tabular}

As perguntas elaboradas não foram fechadas e os participantes puderam explanar suas percepções quanto ao uso do protótipo "ConsumidorAtento".

Perguntados sobre sugestões para melhoria ou correção das funções do protótipo, alguns não sugeriram mudanças e outros sugeriram mudanças na cor do botão da tela inicial que estava com cinza claro para verde; outra sugestão referia-se ao ajustamento da página do disque denúncia para que coubesse na tela do smartphone do usuário; inserir informação sobre a não correlação entre registros de boletim de ocorrência e ação no juizado especial; inserir nas frases de dicas compartilhadas a fonte como "APP ConsumidorAtento" e; ajustes na parte referente a linguagem utilizada ao descrever as leis que envolvem o direito do consumidor.

Dentre todas as sugestões, apenas a que se referia ao ajustamento da página do disque denúncia não foi possível proceder, pois a própria página não é responsiva, ou seja, ela não se adequa a tela do smartphone, pois não reconhece automaticamente que o acesso foi realizado por meio de um dispositivo móvel.

Importante destacar que o protótipo/aplicativo não converte as páginas, ele é um canal que dá acesso tanto a página dentro do próprio programa quanto acesso por meio dos links relacionados a instituições de defesa do consumidor.

A última participação dos pesquisados foi quanto a utilização de duas funções no "ConsumidorAtento". A primeira, o envio de um relato/denúncia diretamente para o e-mail da DECON e a segunda compartilhar duas dicas sobre os direitos do consumidor em uma rede social.

Para ter acesso a todas as funcionalidades do aplicativo "ConsumidorAtento" basta utilizar o código QRCode na figura $4 \mathrm{e}$ baixar e instalar em qualquer dispositivo que rode o sistema Android.

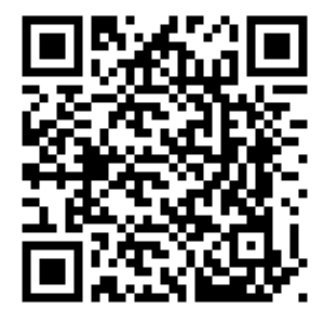

Figura 4. QRCode para baixar "ConsumidorAtento" 


\subsection{Cartilha Informativa}

O segundo produto deste trabalho é a confecção de uma cartilha informativa para ser impressa e distribuída nas delegacias de polícia do Estado de Pernambuco.

Denominada de Cartilha do "ConsumidorAtento" possui o mesmo conteúdo que foi desenvolvido para o aplicativo, com uma linguagem simples.

A cartilha será utilizada como material para o curso de direito do consumidor a ser oferecido aos policiais de outras delegacias da região metropolitana do Recife e interior de Pernambuco. Este curso será na modalidade de Educação a Distância, pois existem muitas delegacias no estado e poucos policiais que possam oferecer um atendimento mais adequado que a temática necessita. Desta forma, um curso em $\mathrm{EaD}$, abarcará muitos profissionais num mesmo espaço de tempo e espaços distintos.

O curso terá duração de 30 horas aula com um período de duração de trinta dias e com emissão de certificado pela DECON.

Na figura 5 é possível visualizar o layout da cartilha que será utilizado no curso.

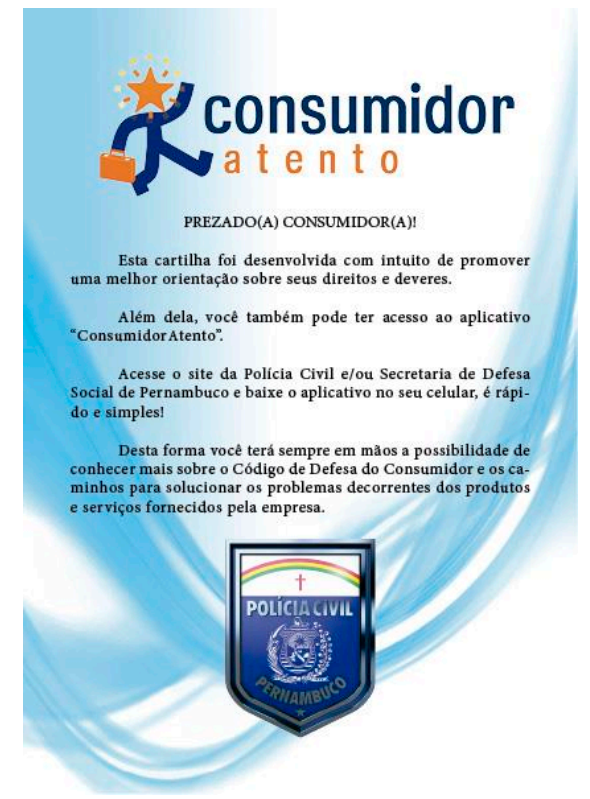

Figura 5. Layout da cartilha "ConsumidorAtento"

A cartilha possui doze páginas contendo o detalhamento das dúvidas dos consumidores que foram identificadas e confirmadas por esta pesquisa, com tamanho A5 $(148 \mathrm{mmx} 210 \mathrm{~mm})$ na versão impressa.

\section{CONCLUSÃO E TRABALHOS FUTUROS}

Diante do conhecimento empírico que deu início a esta pesquisa e posteriormente após a confirmação por meio da coleta de dados secundários e produção dos primários, bem como, da realização de uma revisão da literatura, percebe-se a necessidade subjacente de disponibilização de uma ferramenta que proporcione ao consumidor a informação acerca de seus direitos, enquanto cidadão, nas relações de consumo.
Os trabalhos voltados para o conteúdo relacionado ao direito do consumidor e promovidos por meio da $\mathrm{EaD}$ disponíveis a população são praticamente ausentes. Foram identificadas duas ações voltadas, nesta perspectiva, no âmbito do governo federal. Em ambas, o conteúdo fornecido é através de cursos que exigem matrícula e certa dedicação de tempo para conclusão.

Propõem-se então, através da tecnologia móvel, o acesso a informação voltado para a promoção do direito do consumidor, ou seja, por meio do m-learning e da gestão do conhecimento.

Diante disto, o aplicativo "ConsumidorAtento" surgiu como alternativa viável, de fácil acesso aos consumidores e com grande possibilidade de atingir o maior número de usuários, pois, foi pensado para uso na plataforma Android que detêm $79 \%$ dos usuários em telefonia móvel no mundo [24].

Seu conteúdo foi desenhado com base nos conceitos que norteiam a aprendizagem móvel atreladas a gestão do conhecimento.

A elaboração de uma cartilha informativa, o segundo produto da pesquisa, foi produzida e será impressa e disponibilizada tanto na DECON quanto em outras delegacias de grande circulação na RMR e interior do Estado de Pernambuco.

Os passos seguintes referem-se à elaboração de um curso na modalidade EaD para que multiplicadores possam participar de cursos ofertados pela DECON na área de direito do consumidor. A cartilha desenvolvida será utilizada para a Educação a Distância neste processo.

O público alvo para este curso são servidores que trabalham nas Delegacias de Polícia do Estado de Pernambuco, além de profissionais que atendem a população na temática de direito do consumidor.

A pesquisa realizada não possui um fim em si mesma, abre novas possibilidades no uso da $\mathrm{GC}$ e da aprendizagem móvel na área policial. O uso de TIC's atreladas a GC com a promoção dos direitos do consumidor foi um ponto inicial.

A necessidade imperiosa de novas formas de acesso a informação para a diminuição da violência, tão alarmante nos dias atuais, poderá iniciar um novo ciclo de realizar políticas públicas mais eficazes e menos onerosas.

Um novo passo está sendo dado no âmbito da esfera pública, especificamente na Polícia Civil de Pernambuco, com a disponibilização do primeiro aplicativo e cartilha, aproximando o cidadão da polícia/poder público.

\section{REFERÊNCIAS}

[1] Zeide, E. \& Liebowitz, J. 2012. Knowledge management in law: A look at cultural resistance. Legal Information Management, 12(1), 34-38.

[2] Stewart, T. A riqueza do conhecimento. Rio de Janeiro: Campus, 2002. Reaich, B. H., Gemino, A. \& Sauer, C. (2012). Knowledge management and projectbased knowledge in it projects: A model and preliminary empirical results. International Journal of Project Management, 30(6), 663-674

[3] Hsu, I.-C. \& Sabherwal, R. 2012. Relationship between intellectual capital and knowledge management: An empirical investigation. Decision Sciences, 43(3), 489-524.

[4] Baskerville, R. \& Dulipovici, A. 2006. The theoretical foundations of knowledge management. Knowledge Management Research \& Practice, 4(2), 83-105. 
[5] Teixeira-Filho, J. 2000. Gerenciando o Conhecimento: Como a empresa pode usar a memória organizacional e a inteligência competitiva no desenvolvimento dos negócios. Rio de Janeiro, RJ: Editora SENAC.

[6] Angeloni, M. T. 2002. Organizações do conhecimento: infraestrutura, pessoas e tecnologias. São Paulo: Saraiva.

[7] Schuelter, G., Coelho, C. S. R. 2010. Gestão do conhecimento nos sistemas de educação a distância: técnicas e ferramentas para melhorar o processo de produção. Florianópolis. Disponível em www.abed.org.br/congresso2010/cd/152010184116.pdfAces so em 01 mar. 2017.

[8] Nonaka, I.; Takeuchi, H. 1997. Criação de Conhecimento na Empresa. Rio de Janeiro: Ed. Elsevier.

[9] Traxler, J. (2007). Defining, Discussing and Evaluating Mobile Learning: the moving finger writes and having writ ... The International Review of Research in Open and Distance Learning, 8(2). Disponível em http://www.educause.edu/Resources/DefiningDiscussingand Evaluatin/161878 acesso em 10 de mar de 2017.

[10] Petrova, K. and Li, C. (2009). "Focus and Setting in Mobile Learning Research: A Review of the Literature" In: Proceedings of the 11th International Business Information Management Conference (IBIMA) on Innovation and Knowledge Management in Twin Track Economies, January, Cairo, Egypt.

[11] Keegan, Desmond. (2005). The incorporation of mobile learning into mainstream education and training. Paper presented: 4th World conference on mLearning - mLearn 2005, South Africa: Cape Town.

[12] UNESCO. (2014) O Futuro da aprendizagem móvel: implicações para planejadores e gestores de políticas. Brasilia: UNESCO.

[13] TARTUCE, F., Neves, D. A. A. 2014. Manual de direito do consumidor: direito material e processual.- 3. ed. - Rio de Janeiro: Forense: São Paulo: MÉTODO. ISBN: 978-85-3095458-1.

[14] Filomeno, José Geraldo Brito. 2004. In: Grinover, Ada Pelegrini ET AL. Código brasileiro de defesa do consumidor: comentado pelos autores do anteprojeto. 8. ed. Rio de Janeiro: Forense Universitária.

[15] Direito do consumidor. 2014. Coleção Conpedi/Unicuritiba. Organizadores: Orides Mezzaroba / Raymundo uliano Rego Feitosa / Vladmir Oliveira da Silveira / Viviane Coêlho Séllos-Knoerr. Coordenadores : Everton das Neves Gonçalves / Frederico da Costa Carvalho Neto / Viviane Coêlho Séllos-Knoerr. Título independente - Curitiba - PR: vol.8 - $1^{\mathrm{a}}$ ed. Clássica Editora, 531p. : ISBN 978-85-9965196-4.

[16] Bittar, Carlos Alberto. 2003. Direitos do consumidor: código de defesa do consumidor. 6. ed. rev., atual. e ampl. de acordo com o novo Código Civil. Rio de Janeiro: Forense Universitária.
[17] Moodle. Modular Object-Oriented Dynamic Learning Environment. 2017. Disponível em $<$ https://moodle.org/> Acesso em 01 mar 2017.

[18] Manzato, A. J., Santos, A. B. 2012. A elaboração de questionários na pesquisa quantitativa. Departamento de Ciência de Computação e Estatística - IBILCE - UNESP. Disponível em

http://www.inf.ufsc.br/ verav/Ensino_2012_1/elaboracao_qu estionarios_pesquisa_quantitativa.pdf. Acesso em 19 Mai. 2016.

[19] Marconi, M. A.; Lakatos, E. M. 2010. Fundamentos da metodologia científica. 7. ed. São Paulo: Atlas, 297 p.

[20] Oliveira, E. R., Diniz, J. R. B. 2016. Mobile learning e gamification: estratégias para promoção de direitos e ampliação da inteligência coletiva. IV Workshop Sobre Tecnologias Móveis Na Educação. Congresso Brasileiro de Informática na Educação - CBIE.

[21] Valeriano, D. L. 1998. Gerência de projetos: pesquisa, desenvolvimento e engenharia. São Paulo: Makron Books.

[22] Gil, A. C. 2007. Como elaborar projetos de pesquisa. São Paulo: Atlas.

[23] SNDC. Sistema Nacional de Defesa do Consumidor. 2017. Disponível em $<$ https://www.consumidor.gov.br/pages/principal/sndc> Acesso em 01 mar 2017.

[24] Statista. 2015.Portal de Estatísticas. Disponível em: $<$ http://www.statista.com> Acesso em 04 mar. 2017.

[25] Chaparro, F. 1998. Apropiacion social del conocimiento em el processo de construccion de sociedad. In: simpósio de gestão da inovação tecnológica, 20.,1988. Anais... São Paulo: ANPAD.

[26] Davenport, T. H.; Prusak, L. 1998.Conhecimento empresarial: Como as organizações gerenciam o seu capital intelectual. Rio de Janeiro: Campus. 237p.

[27] Sveiby, K. E. 1998. A nova riqueza das organizações: gerenciando e avaliando os patrimônios do conhecimento. Rio de Janeiro: Campus.

[28] Sullivan K. O. 2005. Leveraging knowledge management technologies to manage intellectual capital. In: Stankosky, M. Creating the discipline of knowledge management the latest in university research. Oxford:Elsevier ButterworthHeinemann.

[29] Batista, A. A. V., Vieira, M. J., Cardoso, N. C. S., Carvalho, G. R. P. 2005. Fatores de motivação e insatisfação no trabalho do enfermeiro. Revista da Escola de Enfermagem da USP. 39 (1): 85-91.

[30] Francisco, R. and Santos, E. A. P. 2011. Aplicação da mineração de processos como uma prática para a gestão do conhecimento. VWorkshop on Business Process Management e Simpósio Brasileiro de Sistemas de Informação (SBSI) 2011. Salvador, BA. 447-484.

[31] Gouvêa, M. T. A., Santoro, F. M., Capelli, F. C., Pimentel, M. 2016. Externalização do conhecimento através de Group Storytelling: um estudo de caso em tutoria online. XII Brazilian Symposium on Information Systems, Florianópolis, SC, May 17-20. 